Animal Genetics,

2000, 31, 396-399

SHORT COMMUNICATION

\title{
Convenient genotyping of six myostatin mutations causing double-muscling in cattle using a multiplex oligonucleotide ligation assay
}

\author{
L Karim, W Coppieters, L Grobet, A Valentini, M Georges
}

\section{Summary}

We herein describe a procedure that allows for simultaneous genotyping of six loss-of-function mutations in the bovine myostatin gene associated with the double-muscling phenotype. The proposed method relies on a multiplex oligonucleotide ligation assay and detection of the fluorescently labelled products using automatic sequencers.

Keywords: bovine myostatin gene, doublemuscling phenotype, multiplex oligonucleotide ligation assay

It has recently been shown that loss-of-function mutations in the myostatin gene cause a doublemuscling or muscular hypertrophy $(\mathrm{mh})$ phenotype in cattle (Grobet et al. 1997; Kambadur et al. 1997; McPherron \& Lee 1997; Cappucio et al. 1998; Grobet et al. 1998). So far six such bovine mutations have been described (Fig. 1). (i) An $11 \mathrm{bp}$ deletion (nt821(del11)) resulting in a truncation of the bioactive C-terminal domain of the protein found in Belgian Blue, Blonde d'Aquitaine, Limousine, Parthenaise, Asturiana and Rubea Gallega. (ii) A $G \rightarrow A$ transition at nucleotide position 938 resulting in the substitution of a highly conserved cysteine by a tyrosine (C313Y) reported in Gasconne and Piedmontese. (iii) An insertion/deletion at position 419 counting from the initiation codon, replacing $7 \mathrm{bp}$ with an apparently unrelated stretch of $10 \mathrm{bp}$, revealing a premature stop codon in the N-terminal latency-associated peptide at amino-acid position 140 (nt419(del7ins10)) reported in Maine-Anjou. (iv) $\mathrm{A} \mathrm{C} \rightarrow \mathrm{T}$ transition at nucleotide position 610 yielding a premature stop codon in the N-terminal latencyassociated peptide at amino-acid positions 204 (Q204X) observed in Charolais and Limousine. (v) A G $\rightarrow$ T transversion at nucleotide position 676 also causing a premature stop codon in the

A Valentini

Istituto di Zootecnia, Universita della Tuscia, via de lellis, 01100

Viterbo, Italy

\section{Correspondence: M Georges}

Accepted 22 May 2000 same N-terminal latency-associated peptide at amino-acid position 226 (E226X) identified in Maine-Anjou. (vi) A $\mathrm{G} \rightarrow \mathrm{T}$ transversion at nucleotide position 874 causing a premature stop codon in the bioactive C-terminal domain (E291X) encountered in Marchigiana.

The discovery of this allelic series of loss-offunction mutations disproved the initial hypothesis postulating that double-muscling would be genetically homogeneous, having appeared in Shorthorn first and having then spread from the British Isles to the continent and the rest of the world by migration (Ménissier 1982). It indicates that myostatin has a unique regulatory potential during myogenesis, being a prime target for mutations that dramatically and exclusively affect muscle mass (Lee \& McPherron 1999). It is noteworthy that animals have been identified (particularly in Blonde d'Aquitaine) which exhibit the doublemuscling phenotype yet do not show an altered myostatin amino-acid sequence nor reduced myostatin mRNA concentrations (Poncelet et al. unpublished observations).

The calving difficulties associated with double-muscling have led several breeding organizations to treat this condition as a genetic defect that needs to be eliminated. In specific economic contexts, however, the gains in feed conversion ratio, dressing out percentage and meat quality (increased lean and tenderness) have outweighed the costs of dystocia, leading either to a systematic selection for double-muscled animals or their use in cross breeding (Hanset 1991). Understanding the molecular basis of double-muscling has opened the possibility to select either for or against this phenotype directly at the genotypic level. In this context, a diagnostic test based on allele-specific PCR has previously been described for the nt821(del11) and C313Y mutations (Fahrenkrug et al. 1999). Herein, we describe the development of a diagnostic test aimed at simultaneously detecting one or more of the six previously descibed myostatin mutations in a DNA sample. 
Genotyping of six myostatin mutations using a multiplex oligonucleotide ligation assay

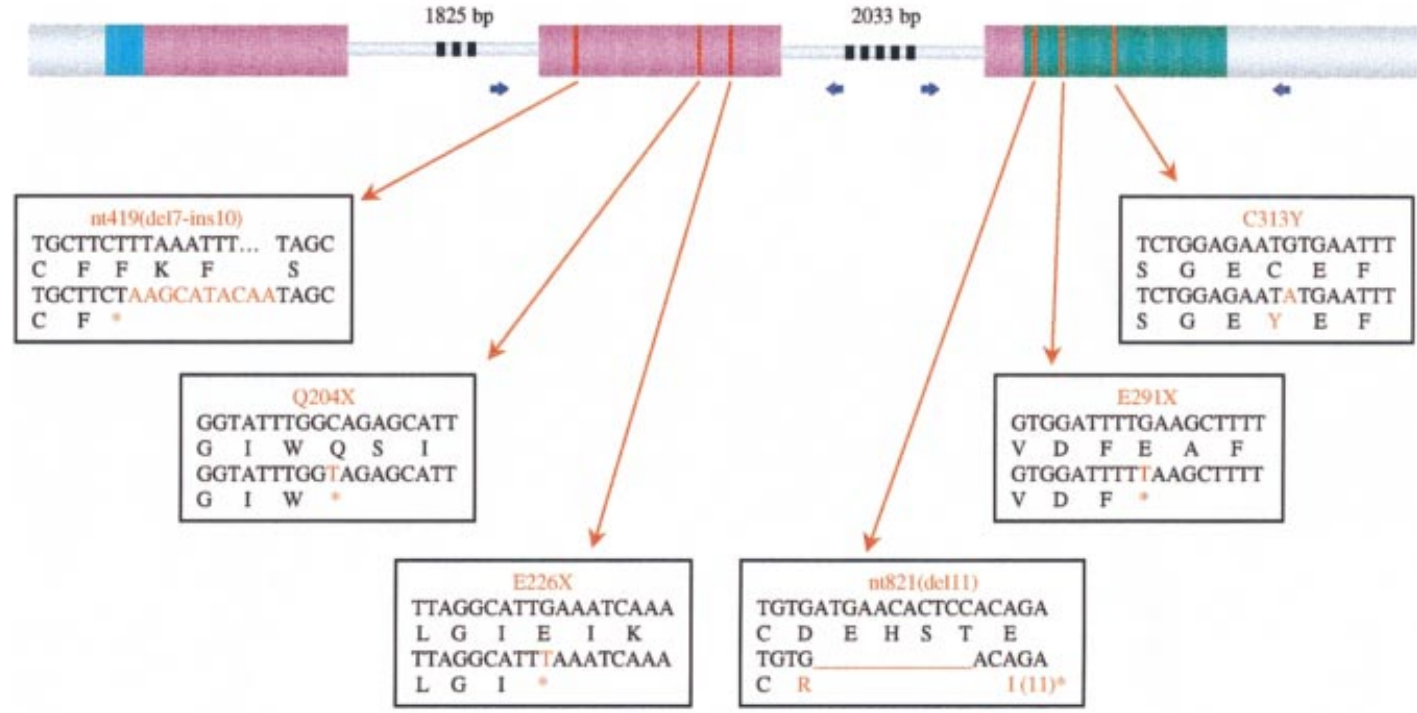

Fig. 1. Schematic representation of the bovine myostatin gene. The grey boxes correspond to the untranslated leader and trailor sequences (large diameter), and the intronic sequences (small diameter). The blue, pink and green boxes correspond to the sequences coding for the leader peptide, N-terminal latency-associated peptide, and bioactive C-terminal domain of the protein, respectively. The blue arrows represent the two primer pairs used for multiplex amplification of exons II and III, respectively. The corresponding primer sequences are reported in Table 1. The positions of the six bovine loss-of-function mutations are shown as red lines on the myostatin gene. Each mutation is connected via an arrow with a box reporting the details of the corresponding DNA sequence and encoded peptide sequence. In each box the mutation is compared with the wild-type sequence, and differences highlighted in red.

The test is based on the simultaneous amplification of the second and third myostatin exons using primers located respectively in intron I and intron II, and intron II and 3' UTR (Table 1). PCR amplification was performed in $10 \mu \mathrm{l}$ reactions using $25 \mathrm{ng}$ of template DNA in the pres-

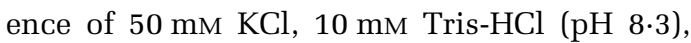
$3 \mathrm{mM} \mathrm{MgCl}_{2}, 300 \mu \mathrm{M}$ of each of the four dNTP, $0.5 \mu \mathrm{M}$ of each of the six primers and $1 \mathrm{U}$ of AmpliTaq ${ }^{\mathrm{TM}}$ Gold polymerase (Perkin-ElmerRoche, Blanchburg, NJ, USA). This reaction mix was subjected to 30 cycles including: (i) a denaturation step at $95{ }^{\circ} \mathrm{C}$ for $1 \mathrm{~min}$ (except first cycle: $5 \mathrm{~min}$ ); (ii) an annealing step at $60^{\circ} \mathrm{C}$ for $1 \mathrm{~min}$; and (iii) an extension step at $72^{\circ} \mathrm{C}$ for 1 min. At the end of the PCR reaction, the Taq DNA polymerase was inactivated at $99^{\circ} \mathrm{C}$ for $30 \mathrm{~min}$.

Five microlitres of this PCR reaction were then used as template in a multiplex oligonucleotide ligation reaction (OLA) (Grossman et al.
1998). The OLA was performed in the presence of 18 primers corresponding to $6 \times 3$ primers per loss-of-function mutation (Table 2). A common $3^{\prime}$ primer was phosphorylated at its $5^{\prime}$ end and extended with three to eight 18-atom spacer arms (Spacer $^{\mathrm{TM}}$ Phosphoramidite-CLONTECH, Palo Alto, CA, USA) at its $3^{\prime}$ end in order to spread the molecular weight of the OLA products corresponding to the different mutations. This allowed them to be easily separated by gel electrophoresis. The two allele-specific $5^{\prime}$ primers were labelled at their $5^{\prime}$ end with distinct fluorophores: HEX (PE Applied Biosystems, Foster City, CA, USA) for the wild-type allele and 6-FAM (PE Applied Biosystems) for the double-muscling allele. The OLA reaction was performed in a final volume of $20 \mu \mathrm{l}$ in the presence of $20 \mathrm{~mm}$ Tris-HCl (pH 7.5), $20 \mathrm{~mm}$ $\mathrm{KCl}, 10 \mathrm{mM} \mathrm{MgCl}_{2}, 0.1 \%$ Nonidet $\mathrm{P} 40,10 \mu \mathrm{M}$ NAD, $1 \mathrm{~mm}$ DTT, $20 \mu \mathrm{M}$ of each primer and $5 \mathrm{U}$ of thermostable TSC DNA ligase (Boehringer

Table 1. Primers for PCR amplification

\begin{tabular}{|c|c|c|}
\hline & UP-primer & DN-primer \\
\hline Exon II & 5'-GTTCATAGATTGATATGGAGGTGTTCG-3' & 5'-ATAAGCACAGGAAACTGGTAGTTATT-3' \\
\hline Exon III & 5'-GAAATGTGACATAAGCAAAATGATTAG-3' & 5'-ATACTCWAGGCCTAYAGCCTGTGGT-3' \\
\hline
\end{tabular}


Karim, Coppieters, Grobet, Valentini, Georges

Table 2. Primers for the OLA reaction

\begin{tabular}{llll}
\hline Mutation & Wild-type & Loss-of-function & Common \\
\hline Nt419(del7-ins10) & HEX-T G(T/C)T TCT TTA & FAM-T TCT AAG CAT & $\begin{array}{l}\text { MP-5'-TAG CTC TAA GAT } \\
\text { AC-(SP)3 }\end{array}$ \\
& AAT T-3' & ACA A-3' & AC-(S' \\
& HEX-C ACT GGT ATT & FAM-C ACT GGT ATT & MP-5'-AGA GCA TTG ATG \\
& TGG C-3' & TGG T-3' & TG-(SP)4 \\
E226X & HEX-C AAC TTA GGC & FAM-C AAC TTA GGC & MP-5'-AAA TCA AAG CTT \\
& ATT G-3' & ATT T-3' & TA-(SP)5 \\
nt821(del11) & HEX-GTG ATG AAC ACT & FAM-TGG GCT TGA TTG & MP-5'-ACA GAA TCT CGA \\
& CC-3' & TG-3' & TG-(SP)6 \\
C313Y & HEX-TG CTC TGG AGA & FAM-TG CTC TGG AGA & MP-5'-TGA ATT TGT ATT \\
& ATG-3' & ATA-3' & TT-(SP)7 \\
& HEX-AA CTG TGG ATT & FAM-AA CTG TGG ATT & MP-5'-AAG CTT TTG GAT \\
& TTG-3' & TTT-3' & GG-(SP)8 \\
\hline
\end{tabular}

Mannheim, Lowes, UK). This reaction mix was subjected to 40 cycles including: (i) a denaturation step at $94^{\circ} \mathrm{C}$ for $30 \mathrm{~s}$ (except first cycle, $2 \mathrm{~min}$ ); and (ii) a ligation step at $39^{\circ} \mathrm{C}$ for $3 \mathrm{~min}$. The TsC DNA ligase was then heat inactivated at $99{ }^{\circ} \mathrm{C}$ for $10 \mathrm{~min}$.

One microlitre of this OLA reaction was mixed with loading buffer ( $3 \mu$ l of formamide, $0.5 \mu \mathrm{l}$ of dextran blue), denatured for $5 \mathrm{~min}$ at $95^{\circ} \mathrm{C}$, loaded on a conventional denaturing $6 \%$ PAGE sequencing gel, and electrophoresed using an ABI373 automatic sequencer. The resulting gel files were analysed with the Genescan software (PE Applied Biosystems). Figure 2 il-

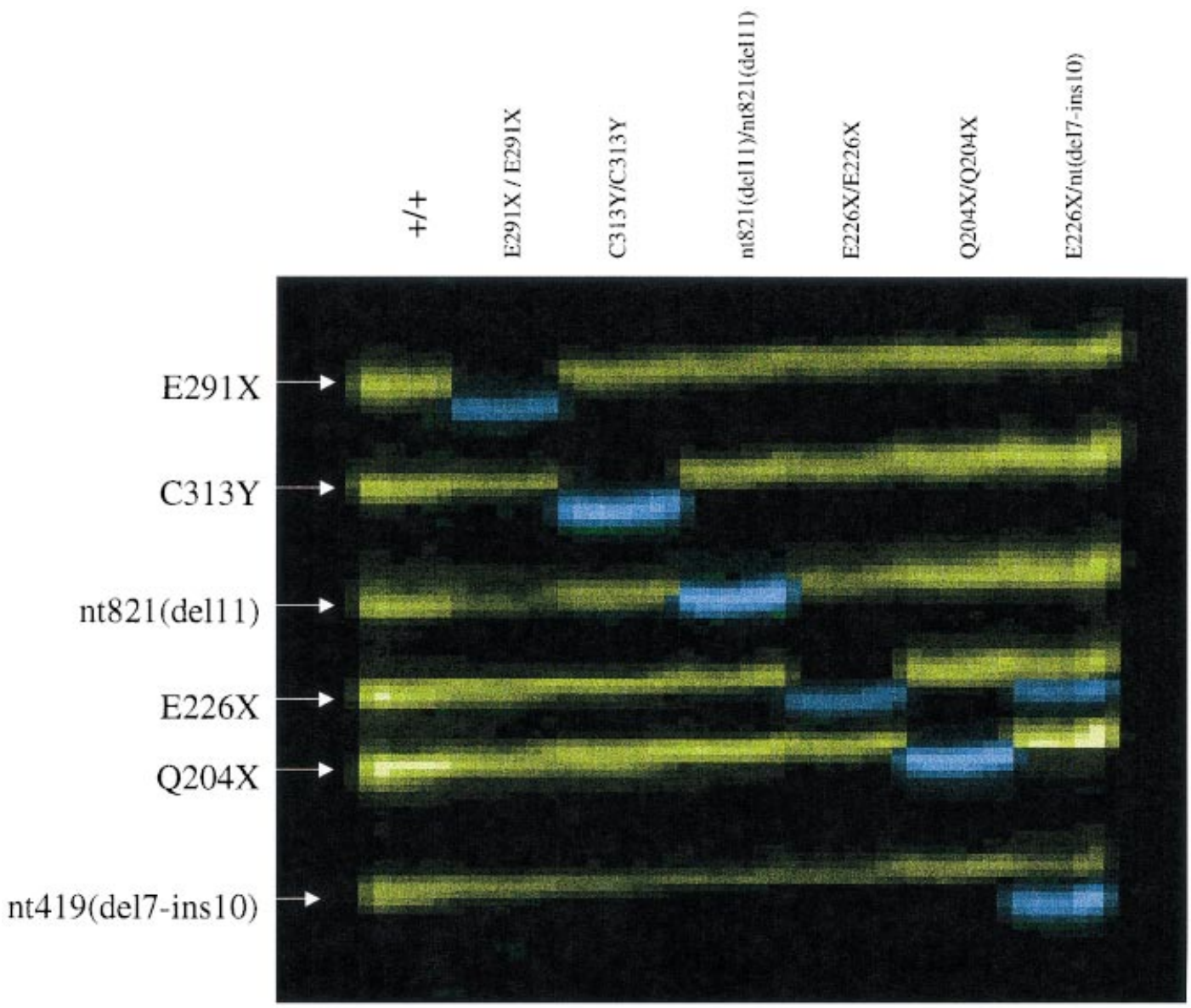

Fig. 2. Results of the multiplex OLA test for the diagnosis of MSTN loss-of-fucntion mutation performed for seven animals. The position of the OLA products corresponding to the six known MSTN mutations are shown on the left. Yellow bands correspond to the wild-type alleles and blue bands to the corresponding mutations. The deduced genotypes of the seven animals are indicated above the figure. 
Genotyping of six myostatin mutations using a multiplex oligonucleotide ligation assay lustrates the typical patterns obtained from such experiments.

To verify its accuracy, we performed the OLA diagnostic test on genomic DNA from 32 previously described double-muscled indivuals representing 10 different continental breeds (Grobet et al. 1998), a double-muscled Marchigiana animal (Cappucio et al. 1998) and two controls (Holstein-Friesian and Jersey). The genotype of these individuals had previously been determined by sequencing their entire myostatin coding sequence. All results obtained with the OLA test were in perfect agreement with the sequencing data (data not shown).

\section{Acknowledgements}

This work was funded by the Belgian Ministry of Agriculture, Skye PharmaTech-Toronto and EU grant BIO4-CT98-0421 (EuroMH).

\section{References}

Cappucio I., Marchitelli C., Serracchioli A., Nardone A., Filippini F., Ajmone-Marsan P. \& Valentini A. (1998) A G-T transversion introduces a stop codon at the mh locus in hypertrophic Marchigiana beef subjects. Animal Genetics 29(Suppl. 1), 51.

Fahrenkrug S.C., Casas E., Keele J.W. \& Smith T.P. (1999) Technical note: direct genotyping of the double-muscling locus $(\mathrm{mh})$ in Piedmontese and Belgian Blue cattle by fluorescent PCR. Journal of Animal Science 77, 2028-30.

Grobet L., Royo Martin L.J., Poncelet D. et al. (1997) A deletion in the myostatin gene causes doublemuscling in cattle. Nature Genetics 17, 71-4.

Grobet L., Poncelet D., Royo Martin L.J., Brouwers B., Pirottin D., Michaux C., Ménissier F., Zanotti M., Dunner S. \& Georges M. (1998) Molecular definition of an allelic series of mutations disrupting the myostatin function and causing double-muscling in cattle. Mammalian Genome 9, 210-3.

Grossman P.D., Bloch W., Brinson E., Chang C.C., Eggerding F.A., Fung S., Iovannisci D.M., Woo S. \& Winn-Deen E.S. (1998) High-density multiplex detection of nucleic acid sequences: oligonucleotide ligation assay and sequence-coded separation. $\mathrm{Nu}$ cleic Acids Research 22, 4527-34.

Hanset R. (1991) The major gene of muscular hypertrophy in the Belgian Blue Cattle breed. In: Breeding For Disease Resistance in Farm animals (ed. by J.B Owen \& R. F.E. Axford), pp. 476-8. CAB International.

Kambadur R., Sharma M., Smith T.P.L. \& Bass J.J. (1997) Mutations in myostatin (GDF8) in doublemuscled Belgian Blue Cattle. Genome Research 7, 910-6.

Lee S.J. \& McPherron A.C. (1999) Myostatin and the control of skeletal muscle mass. Current Opinions in Genetics and Development 9, 604-7.

McPherron A.C. \& Lee S.J. (1997) Double muscling in cattle due to mutations in the myostatin gene. Proceedings of the National Academy of Sciences, USA 94, 12457-61.

Ménissier, F. (1982) Present state of knowledge about the genetic determination of muscular hypertrophy or the double muscled trait in cattle. In: Current Topics in Veterinary Medicine and Animal Science, Vol. 16: Muscle Hypertrophy of Genetic Origin and Its Use to Improve Beef Production (ed. by King, Ménissier \& M. Nijhoff), pp. 387-428. 